\title{
The Influence of Financial Technology on the Business of Commercial Banks and Measure Suggestions
}

\author{
Zhao-Yu Wu* \\ Bank of Kunlun, Beijing 100032, China \\ *Corresponding author: Zhao-Yu Wu, wuzhaoyu731@163.com
}

Copyright: (C) 2022 Author(s). This is an open-access article distributed under the terms of the Creative Commons Attribution License (CC BY 4.0), permitting distribution and reproduction in any medium, provided the original work is cited.

\begin{abstract}
With the continuous development and improvement of financial technology, commercial banks are facing huge impacts and challenges brought about by financial technology, but what follows is a huge opportunity for the transformation of commercial banks. Therefore, this research analyzes the four aspects of the impact of financial technology on commercial banks, and explores the challenges that financial technology brings to commercial banks' development strategies, traditional businesses, and business processes. For the measures taken, commercial banks need to improve the financial technologyrelated infrastructure, and improve the main functions of supervision technology and the transformation of cultural values. This research provides theoretical basis and implementation suggestions for the transformation of commercial banks through theoretical research.
\end{abstract}

Keywords: Financial technology; Commercial bank; Cloud computing technology; Big data technology

Online publication: January 19, 2022

\section{Introduction}

With the rapid development of computer technology, the gradual maturity of blockchain technology, cloud computing technology and big data technology, the development of financial technology has also ushered in a climax ${ }^{[1]}$. Internet financial products are gradually gaining popularity. Third-party payment, small loans and other businesses gradually replace the original business of commercial banks, gradually intensifying the competition of banking business; therefore, many commercial banks are facing this huge challenge ${ }^{[1-3]}$. In recent years, people have gotten a taste of the convenience of financial technology to our daily life. People can enjoy fast loan business without applying for a credit card, and plan funds through APPs such as funds and wealth management. This has gradually broken the monopoly of commercial banks, thereby re-dividing the market share of banks ${ }^{[4-6]}$. Therefore, the transformation of commercial banks is imperative. In view of this, this paper analyzes the impact of financial technology on commercial banks and the challenges it brings, and then summarizes the commercial bank transfer strategies which are recommended for the transformation of commercial banks.

\section{Literature review}

Internet finance was first proposed by Western scholars. Scholars such as Claessens S (2002) proposed that online banking and online economy are the main Internet financial carriers ${ }^{[7]}$. Chinese scholar Zhipeng Bai 
(2015) pointed out in a related article that Internet finance will cause a crisis for traditional commercial banks, and it will also prompt traditional commercial banks to find new transformation directions, improve bank management efficiency, and reduce commercial bank operating costs ${ }^{[8,9]}$.

Fintech is to rely on computer technology to innovate the financial industry. Fintech mainly emphasizes the coordination and common development between financial development and technological development ${ }^{[9-11]}$. The information technology that financial technology relies on includes big data technology, Internet of Things technology, cloud computing technology, artificial intelligence technology, etc. ${ }^{[9,12]}$ The financial industry using technology as the main driving force can improve operating efficiency and reduce operating costs, and better increase the user experience; this will definitely leave a huge impact on the traditional commercial banks ${ }^{[1,3,4]}$.

\section{The impact of financial technology on commercial banks}

\subsection{Competition in the banking industry is gradually increasing}

With the emergence of financial technology, the rapid development and transformation of Internet finance, the competition in the commercial banking industry has gradually increased. This is because the group of commercial banks is fixed, but with the addition of foreign banks and Internet finance, commercial banks are increasing. The monopoly of Hengye has been broken, and the industry competition of banks has gradually increased. The rapid integration and development of big data technology, cloud computing technology, blockchain technology, Internet of Things technology and the financial industry have completely changed the pattern and development of the entire banking industry. With the rapid development of information technology, financial technology-related companies have developed a strong reputation in the user's psychology in terms of data security, user privacy, and efficiency. This has a great impact on the business of commercial banks. Therefore, various commercial banks have begun to develop financial technology sectors, changing the traditional banking competition model to comprehensive strength competition and innovative competition models. This form of industry competition has been gradually intensifying.

\subsection{The operating income of commercial banks has decreased rapidly}

The operating income of commercial banks is mainly derived from the difference between the interest rate of the deposit business and the interest rate of the loan business, followed by some intermediary businesses as the main source of income. However, with the participation of fintech institutions in the banking industry, the number of deposit business customers of banks has gradually decreased, because business products such as Yu'ebao and Lingqiantong in fintech institutions are not only easy to operate, but also have high interest rates, and have the advantages of taking and using them. The gradual removal of bank deposit business customers has caused more panic in commercial banks. Secondly, with the continuous innovation of financial products of financial technology institutions, many computer software products include loan platforms or loan functions. These loan products, owing to their fast review speed, simple application materials, and product diversification, have attracted a large number of commercial bank users. These products have seriously affected the development of commercial banks' credit card business, although they did not affect commercial banks' car loans. Housing loans, but the impact on the bank's loan business is also very serious. In order to reduce this impact, commercial banks began to reduce bank loan interest rates and increase bank deposit interest rates, which ultimately led to a rapid decline in commercial banks' operating income year by year.

The intermediate business of commercial banks, such as payment and settlement business, is one of the traditional intermediate businesses in commercial banks. However, due to the third-party payment and 
mobile payment functions of financial technology institutions, the use of computing technology is acute and efficient for customer information. The storage and use of payment and settlement services has improved the information asymmetry and untimely phenomenon of payment and settlement services. Therefore, almost $90 \%$ of the customers of commercial banks are using third-party payment. In addition, with the continuous development of technology, China continues the effort to develop digital currency, which is an encrypted currency with blockchain technology as the core and uses distributed transactions without commercial banks as an intermediate system for transactions. As the trial of digital currency continues, discussions on the advantages and disadvantages of digital currency are constantly emerging.

\subsection{The credit function of commercial banks is gradually weakening}

The credit function of commercial banks has a very important role in finance, but with the emergence and development of financial technology institutions, the function of this role is constantly weakening or even disappearing. Financial technology refers to the use of computer technology to carry out financial innovation applications. With the integration of big data technology and cloud computing technology into the user behavior analysis of financial platform, users' untrustworthy behavior will be archived in the Internet records, which will update and affect user ratings in real time. Internet finance does not need to complete user information ratings based on bank credit records. Banks are also unable to participate in Internet financial transactions. Therefore, the business capabilities of commercial banks have weakened.

\subsection{Difficulties in maintaining bank customer relationships}

Fintech has a great impact on the customer relationship of commercial banks. First, many young people no longer go to the bank to handle business, and it is difficult to maintain the customer relationship of bank account managers. Secondly, many older users have a lot of influence on bank operations and processes. Without a clear understanding, it is impossible to expand the new business among the elderly users.

\section{Challenges faced by commercial banks in the context of financial technology}

\subsection{Fintech challenges the development strategy of commercial banks}

Financial technology has impacted the dominant position of commercial banks with powerful technological innovations, making commercial banks aware of their own development limitations and shortcomings. Therefore, the future development strategy of commercial banks should be to study and continue to apply the latest technology. The optimization of the development strategy creates the latest financial model that adapts to the current development model.

\subsection{Fintech challenges the traditional business of commercial banks}

With the integration of computer technology and finance, the gradual expansion and development of Internet financial services, third-party payment services, P2P decentralized services, and small loan services have brought serious challenges to the development of commercial banks. In 2017, the online payment business volume of non-bank payment institutions in China reached 286.747 billion, involving an amount of 143.26 trillion yuan, a year-on-year increase of $74.95 \%$ and $44.32 \%$, respectively ${ }^{[9]}$.

\subsection{Fintech challenges the business process of commercial banks}

In the business process of a commercial bank, the commercial banking system is divided into two parts: the foreground and the background. This separation of the system makes the transaction through the commercial bank complicated and takes a long time. At present, with the rapid development of computer 
technology, cloud computing technology, big data technology and other technologies can shorten transaction time, simplify transaction processes, and improve user experience. Therefore, financial technology poses challenges to the business processes of commercial banks.

\section{Suggestions of commercial banks under the background of financial technology}

\subsection{Improve the infrastructure of financial technology}

As mentioned in the analysis in the previous two section, commercial banks need to focus on the integration of financial technology to form a complete financial technology rapid facility, in order to successfully transform the bank into a new type of commercial bank. The main requirements for a complete basic design are the commercial bank's front-end system and back-end system. The system merges, and integrates cloud computing technology and big data technology, and rationally arranges the position of the business in the system. Secondly, it is to optimize the human-computer interaction link in the commercial banking system to enhance the user experience.

For the integration of financial technology, commercial banks need to strengthen the cooperation between commercial banks and technology companies to enhance the hardware and software capabilities of industrial banks. The first requirement is high-performance computer equipment and cloud processors for hardware equipment, followed by software facilities and distributed storage, artificial intelligence recommendation algorithm, data mining and computing technology.

Finally, commercial banks should rely on information technology to transform the internal organizational structure of commercial banks, change existing business processes, products and services, realize information and data sharing, and solve customer problems in a one-stop manner.

\subsection{Improve the main functions of regulatory technology}

With the development and improvement of financial technology in the financial industry, the concept of regulatory technology has gradually been proposed. Regulatory technology includes the innovative development of regulatory systems, rules, policies and concepts. The first thing to do is to use technology for financial products in gray areas. In the supervision aspect, pre-preemptive supervision methods should be adopted, and a steady integration of financial technology and commercial banks in risk management and efficiency should be gradually realized.

\subsection{Facilitate the transformation of cultural values}

Due to the impact of financial technology, commercial banks need to change their cultural values, detail division of financial service products and financial customers, identify customers' pain points, and use financial technology to strengthen commercial bank's financial products to solve problems, so as to occupy a share of the new financial market.

\section{Conclusion}

This paper analyzes the four aspects of the impact of financial technology on commercial banks, and explores the challenges brought by financial technology to commercial banks' development strategies, traditional businesses, and business processes. Finally, we made several recommendations on the measures the commercial banks should take under the background of financial technology. Commercial banks need to improve the financial technology-related infrastructure and the main functions of regulatory technology; ultimately, they need to complete the transformation of cultural values, so as to better transform into a new type of commercial bank under the background of financial technology and regain a share of the market. 


\section{Disclosure statement}

The author declares no conflict of interest.

\section{Author contributions}

ZY.W. conceived the idea of the manuscript and wrote the paper.

\section{References}

[1] Qiu H, Huang Y, Ji Y, et al., 2018, The Impact of Financial Technology on Traditional Banking Behaviors: Based on the Perspective of Internet Financing. Financial Research, 461(11): 17-30. http://doi.org/10.12094/1002-7246

[2] Hu B, Research on the Development Countermeasures of CCB Hongdu Sub-Branch under the Background of Internet Finance.

[3] Zhang D, Jiang L, 2018, The Enabling Role and Path of Financial Technology in the Transformation of Traditional Commercial Banks. Southwest Finance, 0(11): 13-19.

[4] Xiao K, Peng Z, Hu D, 2019, Research on Challenges and Countermeasures of Digital Transformation of Commercial Banks in the Era of Fintech. Agricultural Bank of China, 0(4): 26-29.

[5] Mckechnie S, Winklhofer H, Ennew C, 2006, Applying the Technology Acceptance Model to the Online Retailing of Financial Services. International Journal of Retail and Distribution Management, 34(4-5): 388-410. http://doi.org/10.1108/09590550610660297/FULL/XML

[6] Wisskirchen C, Vater D, Wright T, et al., 2006, The Customer-Led Bank: Converting Customers from Defectors into Fans. Strategy and Leadership, 34(2): 10-20. http://doi.org/10.1108/10878570610652590/FULL/XML

[7] Claessens S, Glaessner T, Klingebiel D, 2002, Electronic Finance: Reshaping the Financial Landscape Around the World. Journal of Financial Services Research, 22(1): 29-61. http://doi.org/10.1023/A:1016023528211

[8] Bai Z, 2015, Opportunities and Challenges of Internet Finance for Small and Medium Commercial Banks. Shanghai Commercial, 0(10): 96-101.

[9] Science Cat. Talking about the Impact of Financial Technology on Commercial Banks and Countermeasures Under the New Situation. http://www.scicat.cn/yy/20211013/42908.html

[10] Challenges and Impacts of Financial Technology on My Country' S Commercial Banks. Billion Euros. https://www.iyiou.com/analysis/2019042598379

[11] Challenges and Countermeasures Faced by Commercial Banks in the Context of Financial Technology._Da Ting Electronic Analysis Network. https://www.zjhzmr2009.cn/syzn/220660.html

[12] Mckechnie S, Winklhofer H, Ennew C, 2006, Applying the Technology Acceptance Model to the Online Retailing of Financial Services. International Journal of Retail and Distribution Management, 34(4-5): 388-410. http://doi.org/10.1108/09590550610660297/FULL/XML 